\title{
A questão interpretativa no contexto de Cister no testemunho do Manuscrito Musical 32 do Arquivo Distrital de Évora
}

\author{
Filipe Santos Mesquita de Oliveira \\ Universidade de Évora \\ filipe.mesquita.oliveira@gmail.com
}

Filipe Mesquita de Oliveira, Doutorado em Música e Musicologia pela Universidade de Évora, é actualmente Professor Auxiliar nessa instituição. O seu domínio de especialização é a música instrumental ibérica dos séculos XVI e XVII, em particular a de tecla. Tem vindo a desenvolver trabalho de investigação em torno da música instrumental portuguesa também noutros períodos históricos, nomeadamente, no período final do Antigo Regime. Como conferencista destacam-se diversas apresentações em Portugal e no Estrangeiro: Thirteenth Biennial International Conference on Baroque Music (Leeds, 2008), Medieval-Renaissance Music Conference (Utrecht, 2009, Barcelona 2011 \& Birmingham 2014), 1st \& 2nd International Conference on Keyboard Historical Music (Edinburgh, 2011 \& 2014), Performa'11 (Aveiro, 2011), ENIM I \& II (Porto, 2011 \& Castelo Branco 2012), Instrumental Music in the Iberian World 1760-1820 (Lisboa, FCG, 2013), Investigação em Arte(s): Perspectivas (Évora, 2013). Entre as suas publicações mais recentes contam-se: «Some aspects of P-Cug, MM 242: António Carreira's keyboard tentos and fantasias and their close relationship with Jacques Buus's ricercari from his Libro primo (1547)» in Interpreting Historical Keyboard Music - Sources, Contexts and Performance (Farnham: Ashgate, 2013); As recomposições dos ricercari do Libro primo... de Jacques Buus no manuscrito P-Cug MM 242 e a execução instrumental em Portugal em meados do séc. XVI (Performa'11); Contributo ao estudo das obras para tecla atribuídas a António Carreira, «O Velho» (Universidade de Évora-UnIMeM/FCT 2012); A Formação orquestral durante o período final do Antigo Regime no contexto dos fundos musicais da Sé de Évora - O testemunho da obra de Ignácio António Ferreira de Lima (†1818) in Música instrumental no período final do Antigo Regime: contextos, circulação e repertórios (Lisboa: Colibri, 2014).

\section{Resumo}

O Manuscrito Musical 32 do Arquivo Distrital de Évora, com a sigla P-EVad 32, é um códice constituído praticamente por monodia, para além de alguns breves acrescentos polifónicos. Inclui todavia algumas instruções de execução musical, essencialmente na sua parte final, que nos levam ao encontro da questão de execução instrumental. $\mathrm{O}$ presente texto pretende dar uma panorâmica da prática instrumental através do testemunho do Manuscrito Musical 32, cujas anotações posteriormente acrescentadas revelam a sua adaptação a novos critérios estilísticos, um dos quais é a presença cada vez mais acentuada dos instrumentos musicais na liturgia. O códice constitui-se assim como um conjunto de dados sobre a música no espaço cisterciense de S. Bento de Cástris durante praticamente trezentos anos da sua história, revelando também muitos dos segredos que circundam os aspectos teórico-práticos da execução instrumental. 


\begin{abstract}
Musical Manuscript 32 of Évora Council Archive, with the sigla P-EVad 32, is a codex practically consisting of monody, apart from a few brief polyphonic additions. It also includes some instructions as regards musical performance, mainly in its final part, these being related to instrumental performance. This study aims to give an overview of instrumental practice through the testimony of Musical Manuscript 32, whose later added annotations reveal its adaptation to new stylistic criteria, one of which is the increasingly strong presence of musical instruments in the Liturgy. The codex is, though, an important source of information about the Cistercian Music, especially in S. Benedict Castris for almost three hundred years of its history. It also reveals many of the secrets that surround the theoretical and practical aspects of instrumental performance in such an historical context.
\end{abstract}

\title{
Palavras-chave
}

Cister

Manuscrito Musical 32 (P-EVad 32)

Évora

Música instrumental

Códice

A partir de meados do séc. XVI e durante as décadas iniciais de seiscentos, a prática de música instrumental em Portugal centrou-se no culto divino, ora reforçando o repertório vocal polifónico dobrando-o, ora adquirindo progressivamente uma autonomia como segundo momento da própria liturgia. Existe uma série de referências escritas à participação de instrumentos musicais nos ofícios litúrgicos, com destaque para o órgão. Ernesto Gonçalves de Pinho no seu estudo sobre a actividade musical no Mosteiro de Santa Cruz de Coimbra ${ }^{1}$ cita vários cronistas que se pronunciam sobre a prática instrumental. Um deles é o narrador da visita efectuada por D. João III em 1550 ao referido mosteiro que salienta a propósito dos quatro instrumentos de tecla que eram tangidos simultaneamente aquando da entrada do Rei:

O órgão grande, o realejo, outro instrumento real e o craviórgão...que todos faziam uma música e harmonia aprazível. ${ }^{2}$

\footnotetext{
${ }^{1}$ PINHO, Ernesto Gonçalves de, Santa Cruz de Coimbra - Centro de Actividade Musical nos Séculos XVI e XVII, Lisboa, Fundação Calouste Gulbenkian, 1981.

${ }^{2}$ Ibid. p.127 (nota 8): Augusto Mendes Simões de Castro, Notas acerca da vinda e estada de el-Rei D. João $3^{\circ}$ em Coimbra no ano de 1550 e do modo como foi recebido pela Universidade, Separata do Boletim Bibliográfico da B.G.U.C., Vol. I, p. 17.
} 
A conquista pelos instrumentos de uma gradual autonomia foi um processo marcante da evolução musical durante quinhentos. No domínio da música sacra, foram aparecendo uma série de versões instrumentais substitutas de determinadas rubricas litúrgicas, como sejam os jogos de versos destinados ao Kyrie no caso da Missa e dos Salmos, Hinos e versos para o Magnifcat, no âmbito do Ofício. ${ }^{3}$ Os momentos longos da deslocação do clero durante as cerimónias eram também acompanhados por música instrumental, como nos testemunham as diversas crónicas da altura, como esta que ora segue extraída do Ordinário de 1579:

...em fim da terça, dece o conuento a a Capella ...E em se começando a tanger os orgaõos, ou outro instrumento, saem da sacristia os que levam as cruzes \& acolytos \& os cantores.../...\& volto (o celebrante) ao povo estando todos de giolhos excepto o diacono \& subdiacono (deixando de tanger o instrumento ou os orgã̃s) levanta o hymno Pange Lingua, \& o Choro acaba o primeiro uerso: desi tange os orgã̃s ou instrumentos, cõ os qes o cõuento alternati diz os versos desse hym. \& dos mais \& pcede a claustra per esta Ordem...Ficando os cantores em fim de todos... ${ }^{4}$

Tomando a forma miniatural do verso como exemplo do que acabámos de referir, sabemos que, na Península Ibérica entre os séculos XVI e XVIII, os versos eram usados indiscriminadamente para a prática de alternatim, consistindo esta em breves entradas e interlúdios inseridos entre rubricas do Ofício ou da Missa, muitas vezes com uma duração um pouco mais alargada e uma sofisticação estilística significativa. Infelizmente, nas fontes documentais que dispomos, falta quase sempre a indicação do lugar concreto no seio da liturgia onde esses versos seriam inseridos. ${ }^{5}$ Nas Obras de

\footnotetext{
${ }^{3} \mathrm{O}$ verso para órgão é uma peça breve, muitas vezes improvisada, que substituía o verso de um hino, salmo, cântico ou outra rubrica litúrgica cantada pelo coro.

${ }^{4}$ PINHO, Santa Cruz de Coimbra - Centro de Actividade Musical, cit. p. 139 (nota 51): Ordinario dos Canonicos Regulares da Ordem do Bemauenturado nosso padre S. Augustinho, da Congregação de Sancta Cruz de Coimbra, Lisboa, 1579, 141r-141v.

${ }^{5}$ No prefácio à sua edição de uma série de versos ibéricos extraídos de diversos códices, Gerhard Doderer reforça essa ideia - Cf. DODERER, Gerhard, Altiberische Versos - Iberische Musik des 16., 17. und 18. Jahrhunderts für Tasteninstrumente, Heidelberg, Willy Müller.Süddeutscher Musikverlag, 1972; também a musicóloga britânica Bernadette Nelson abordou esta questão, acentuando as múltiplas hipóteses existentes na prática de alternatim - Cf. NELSON, Bernadette, «Alternatim Practice in 17th-Century Spain: The Integration of Organ Versets and Plainchant in Psalms and Canticles» Early Music, Vol. 22 n², May 1994, p. 239-259; ainda Klaus Speer procedeu ao estudo dos verso ibérico no seu contexto formal, estilístico e prático - Cf. SPEER, Klaus, Frei Roque da Conceição - Livro de Obras de Órgão, Lisboa, Fundação Calouste Gulbenkian, 1998 \& SPEER, Klaus, «The Organ Verso in Iberian Music to 1700», JAMS, Vol. 11, No. 2/3 (Summer - Autumn, 1958), p. 189-199.
} 
Música para tecla, arpa e vihuela... de Antonio de Cabezón, publicadas em Madrid em 1578 pelo seu filho Hernando ${ }^{6}$, surgem oito versos, cada um num dos oito modos litúrgicos, precedidos da indicação que se destinariam aos principiantes, para eles se irem familiarizando com a arte da glosa ${ }^{7}$. Há portanto um conteúdo didáctico associado ao verso ibérico para tecla, o qual não podemos ignorar décadas mais tarde, já situados na primeira metade do séc. XVII. Na verdade, tal é o caso dos versos incluídos na parte final das Flores de Música... de Manuel Rodrigues Coelho, colectânea publicada em Lisboa em 1620, os quais, segundo Kastner sublinhou, também serviriam propósitos didácticos ${ }^{8}$.

À guisa de sistematização das questões que conhecemos relativas às práticas organísticas de alternatim, podemos assim afirmar que, no que diz respeito ao verso ibérico para tecla, este se constitui como uma peça de duração muito breve inserida entre os salmos e os cânticos litúrgicos, funcionando como um elo de união entre estes. Muitas vezes existem referências temáticas musicais e/ou formais que nos ajudam a situar determinado verso no contexto de determinada rubrica, o que sucede, por exemplo, com os Versos de Magnificat - Tono primero (XLII) e os quatro versos de Kyrie Rex virginum $(L)$, que se incluem nas Obras de música ... de Cabezón ${ }^{9}$. Porém, na maior parte dos casos, isso não acontece, pelo que apenas sabemos da função litúrgica do verso. No contexto das práticas de alternatim, não era forçoso que o órgão tocasse sempre um verso. Podia apenas tocar o tom ou a sonoridade vertical do cântico seguinte, com isso ajudando o coro a entrar no tom ${ }^{10}$. Por seu lado, a última sonoridade do verso deveria corresponder ao tom de entoação do coro para a execução da rubrica seguinte. Sabemos também que estas miniaturas organísticas, geralmente a três e

\footnotetext{
${ }^{6}$ CABEZÓN, Antonio de, Obras de música para tecla, arpa y vihuela... recopiladas y puestas en cifra por Hernando de Cabezón su hijo, Madrid, Francisco Sanchez, M.D.LXXVIII.

7 Cf. ANGLÉS, Higinio (ed.), Antonio de Cabezón - Obras de música para tecla, arpa y vihuela...recopiladas y puestas en cifra por Hernando de Cabezón su hijo (Madrid, Francisco Sanchez, M.D.LXXVIII), Barcelona, Instituto Español de Musicología, 1966, Vol.I, p. 31.

${ }^{2}$ Cf. KASTNER, Macário Santiago, (ed.), Manuel Rodrigues Coelho: Flores de Música pera o instrumento de tecla \& harpa, Vol. I, Portugaliae Musica, Lisboa, Fundação Calouste Gulbenkian, 1976, p. VII-XII.

9 Cf. ANGLÉS, Higinio (ed.), Antonio de Cabezón - Obras de música para tecla, arpa y vihuela...recopiladas y puestas en cifra por Hernando de Cabezón su hijo (Madrid, Francisco Sanchez, M.D.LXXVIII), Barcelona, Instituto Español de Musicología, 1966, Vol. II, p. 7-12 \& 40-44.

${ }^{10}$ Cf. NELSON, Bernadette, «Alternatim Practice in 17th-Century Spain: The Integration of Organ Versets and Plainchant in Psalms and Canticles» Early Music, Vol. 22 nº2, May 1994, p. 241.
} 
mesmo a duas vozes, tinham simultaneamente uma função didáctica, iniciando organista na prática litúrgica ${ }^{11}$.

Esta problemática relativa à prática instrumental, que acabamos de expor, tornase recorrente quando nos confrontamos com a circulação de manuscritos musicais em Portugal entre os séculos XVI e XVII. Efectivamente, a grande maioria destes códices é de natureza vocal, ora incluindo monodia, ora polifonia. Escassos são pois os testemunhos escritos de música instrumental para execução. Registamos a este propósito, entre outros poucos exemplos, os Manuscritos 48, 52 e 242 da Biblioteca Geral da Universidade de Coimbra, que têm vindo a constituir objecto do nosso estudo. Pelo contrário, em suporte impresso, embora também relativamente escassas, são já de assinalar as obras teórico-musicais subordinadas à prática instrumental, portuguesas ou conhecidas em Portugal, durante este período. Cingindo-nos às nacionais, cite-se, entre outras, a Arte de Tanger de Gonçalo de Baena, impresso em Lisboa, em 1540 ou as já citadas Flores de Música... do Padre Manuel Rodrigues Coelho, também impresso em Lisboa, mas já em 1620.

Paira assim sobre a questão da execução instrumental nesta circunstância cultural e cronológica um questionamento que é legítimo fazermos, para além do mais, à partida, corroborado por registos como, por exemplo, aquele que se refere à existência de inúmeros músicos tangedores nas capelas musicais clericais em Portugal. O cerne desse questionamento assenta assim na dicotomia existente entre, por um lado, a multiplicidade de registos que dispomos referindo músicos oficiantes nas capelas clericais, de norte a sul do país, bem como da compra e da assinatura de contractos para a manufactura de instrumentos musicais, por outro lado de um legado manuscrito quase na sua totalidade constituído por música vocal. Ou seja, para resumir, quase só música vocal manuscrita em confronto com uma plêiade de documentos que atestam a prática intensiva de música instrumental em Portugal, durante este período. É precisamente esse exercício de musicologia histórica que nos impõe o manuscrito musical 32 do Arquivo Distrital de Évora (P-EVad 32).

Antes de passarmos à descrição breve do códice, importa por agora inseri-lo no contexto cisterciense, mais concretamente a sua associação a S. Bento de Cástris. ${ }^{12} \mathrm{O}$

\footnotetext{
${ }^{11}$ DODERER, Gerhard, \& RIPOLL, Miguel Bernal (eds.), A. de Cabezón - Ausgewählte Werke für Tasteninstrumente, Vol. I, Kassel, Bärenreiter, 2010, p. X.

${ }^{12} \mathrm{Na}$ sua Tese de Doutoramento Antónia Conde estudou todo o conjunto de experiência e vivências das monjas de S. Bento de Cástris, tendo procedido ao levantamento de alguns aspectos relacionados com prática musical, como, entre outros exemplos, a identificação das funções das monjas ou a existência de
} 
manuscrito faz parte do conjunto de Livros de Coro oriundos do espólio musical do Mosteiro de S. Bento de Cástris que se encontram repartidos entre duas instituições culturais da cidade de Évora, nomeadamente o Arquivo Distrital e a Biblioteca Pública. No total, contam-se treze Livros de Coro destinados a uso litúrgico no âmbito, quer do Ofício, quer da Missa, dividindo-se entre Antifonários, Graduais e ainda um Hinário. ${ }^{13}$

O manuscrito musical 32 do Arquivo Distrital de Évora, com a sigla P-EVad 32, Contém o Santoral (inicia na festa de S. Estêvão), o Ofício de Defuntos e parte do Kyriale e duas secções do Credo de Mateus d'Aranda (c. 1495-1548). Foi reencadernado e acrescentado em 1738, por encomenda da cantora D. Isabel Cândida Maria Corte Real, tendo sido adicionada uma numeração árabe. No seu trabalho de investigação, Antónia Conde provou a associação desta cantora ao conjunto das monjas de S. Bento de Cástris durante a primeira metade do século XVIII. ${ }^{14}$ Por conseguinte, daí se infere também a associação do códice às práticas musicais deste mosteiro. Tratase de um Gradual quinhentista em pergaminho com 193 fólios e notação quadrada sobre pentagrama, em caligrafia gótica com iniciais ornamentadas a vermelho, azul e preto. ${ }^{15}$ O códice relaciona-se com outros manuscritos musicais do Arquivo Distrital de Évora, nomeadamente, os P-EVad $1 \& 34$, dois livros de coro, que na realidade são apenas um Gradual dividido em dois manuscritos, cuja análise caligráfica pressupõe a mesma mão que copiou o P-EVad 32. ${ }^{16}$ Importa ainda referir que, no contexto dos 13 livros de coro cistercienses repartidos entre o Arquivo Distrital de Évora e a Biblioteca Pública desta cidade, os referidos códices são os únicos graduais do conjunto. ${ }^{17}$ Avançamos também aqui a hipótese dos três manuscritos serem pré-tridentinos, dada a raspagem de muitos trechos de cantochão, por razões de obediência aos ditames tridentinos. Nesse sentido, a datação do início da sua realização poderia ser colocada na primeira metade do século

instrumentos musicais em $\mathrm{S}$. Bento de Cástris. - Cf. CONDE, Antónia Fialho, O mosteiro de S. Bento de Cástris e a Congregação Autónoma de Alcobaça (1567-1776), Universidade de Évora, Tese de Doutoramento em História Moderna, Julho de 2005.

${ }^{13}$ A base de dados aqui referida inclui a informação detalhada a propósito do conjunto dos livros de coro de S. Bento de Cástris - Cf. Livros de Coro/Bases de Dados ORFEUS - Projecto FCT EXPL/EPHPAT/2253 (http:// http://www.orfeus.pt/musica.php).

${ }^{14}$ CONDE, Antónia Fialho, O mosteiro de S. Bento de Cástris e a Congregação Autónoma de Alcobaça (1567-1776), Universidade de Évora, Tese de Doutoramento em História Moderna, Julho de 2005.

15 Cf. Livros de Coro/Bases de dados ORFEUS - Projecto FCT EXPL/EPH-Pat/2253 (http:// http://www.orfeus.pt/musica.php.

16 Ibid.

${ }^{17}$ No seu estudo em torno dos manuscritos musicais cistercienses, Mara Fortu relacionou o conjunto destes três manuscritos, datando-os de quinhentos.- Cf. FORTU, Mara, «Os Manuscritos liturgicomusicais da Ordem de Cister em Portugal e na Galiza» in Actas del IV Congreso Internacional sobre el Císter en Portugal y Galicia, Braga - Oseira, 2010, p. 759. 
XVI, isto é, antes de $1545 .{ }^{18}$ Por outro lado, sabemos também da existência de um coro feminino em Cástris, activo entre os séculos XVI e XVIII, ao qual foram aplicadas as orientações tridentinas. ${ }^{19}$ Dos valiosos dados que podemos extrair dos levantamentos realizado por Antónia Conde destacam-se, não só as funções musicais desempenhadas pelas monjas, mas também os registos dos instrumentos que tocavam. ${ }^{20} \mathrm{~A}$ inscrição inicial na folha de guarda do manuscrito atesta o dado seguinte (v. fig. 1):

«Este livro mandou encadernar e acrescentar a M.R.S.D. Isabel Cândida Maria CorteReal sendo cantora no ano de $1783 »^{21}$

\footnotetext{
${ }^{18}$ Na prossecução do estudo destes três manuscritos, importa confrontá-los, entre outras fontes, com aquelas que foram os produtos mais importantes da reforma tridentina relativa ao cantochão, nomeadamente os, Graduale de Tempore Iuxta ritum sacrosanctae romanae ecclesiae cum cantu Pauli V Pont. Max. iussu reformato. cum privilegio. Romae, Ex Typographia Medicaea, Anno M.DC.XIIII e o Graduale de Sanctis...; a análise de todas as alterações relativas ao cantochão nestes três manuscritos, sobretudo as suas abreviações, sugerem, como referido no corpo de texto do presente estudo, a sua adaptação aos ditames tridentinos. Todavia, essa é, para já, uma tarefa extrínseca ao estudo que aqui redigimos, centrado na problemática interpretativa, ao nível instrumental, no contexto de S. Bento de Cástris. No que respeita aos manuscritos P-EVad $1 \& 34$ relativamente ao estudo das alterações do cantochão que foram fruto das disposições tridentinas, Luís Henriques apresentou-nos recentemente um estudo sobre a questão, a publicar proximamente - Cf. HENRIQUES, Luís, $O$ ciclo do Temporale e Sanctorale em dois graduais quinhentistas do mosteiro de S. Bento de Cástris: A sua organização e intervenções posteriores (comunicação apresentada no âmbito do Seminário Internacional "Arte, Música e Devoção nos Mosteiros da Ordem de Cister" - Casa Museu de Monção/Universidade do Minho, Março de 2015); importa ainda referir que Rui Cabral Lopes problematizou a questão da utilização dos cantus firmi nas missas de Requiem nas fontes portuguesas quinhentistas, sublinhando que, a esse propósito, «O facto de não ter sido constituída uma versão unificada destas melodias no curso do Concílio de Trento, ou mesmo na sequência das actividades reformadores das comissões especializadas que se lhe seguiram, teve como principal consequência a continuação da proliferação de múltiplas variantes das melodias do cantochão a partir de finais do século XVI, mesmo nos livros litúrgicos impressos de uso romano, com influência nítidas no repertório polifónico.» - Cf. LOPES, Rui Cabral, «Os cantus firmi das missas de Requiem da Escola de Manuel Mendes: Aspectos de estrutura musical e de filiação nas fontes portuguesas de música litúrgica» in Revista Portuguesa de Musicologia, Vol. 6, 1996, p. 85.

${ }^{19}$ CONDE, Antónia Fialho, O mosteiro de S. Bento de Cástris e a Congregação Autónoma de Alcobaça (1567-1776), Universidade de Évora, Tese de Doutoramento em História Moderna, Julho de 2005.

${ }^{20}$ Ibid.

${ }^{21}$ Cf. P-EVad 32, folha de guarda.
} 


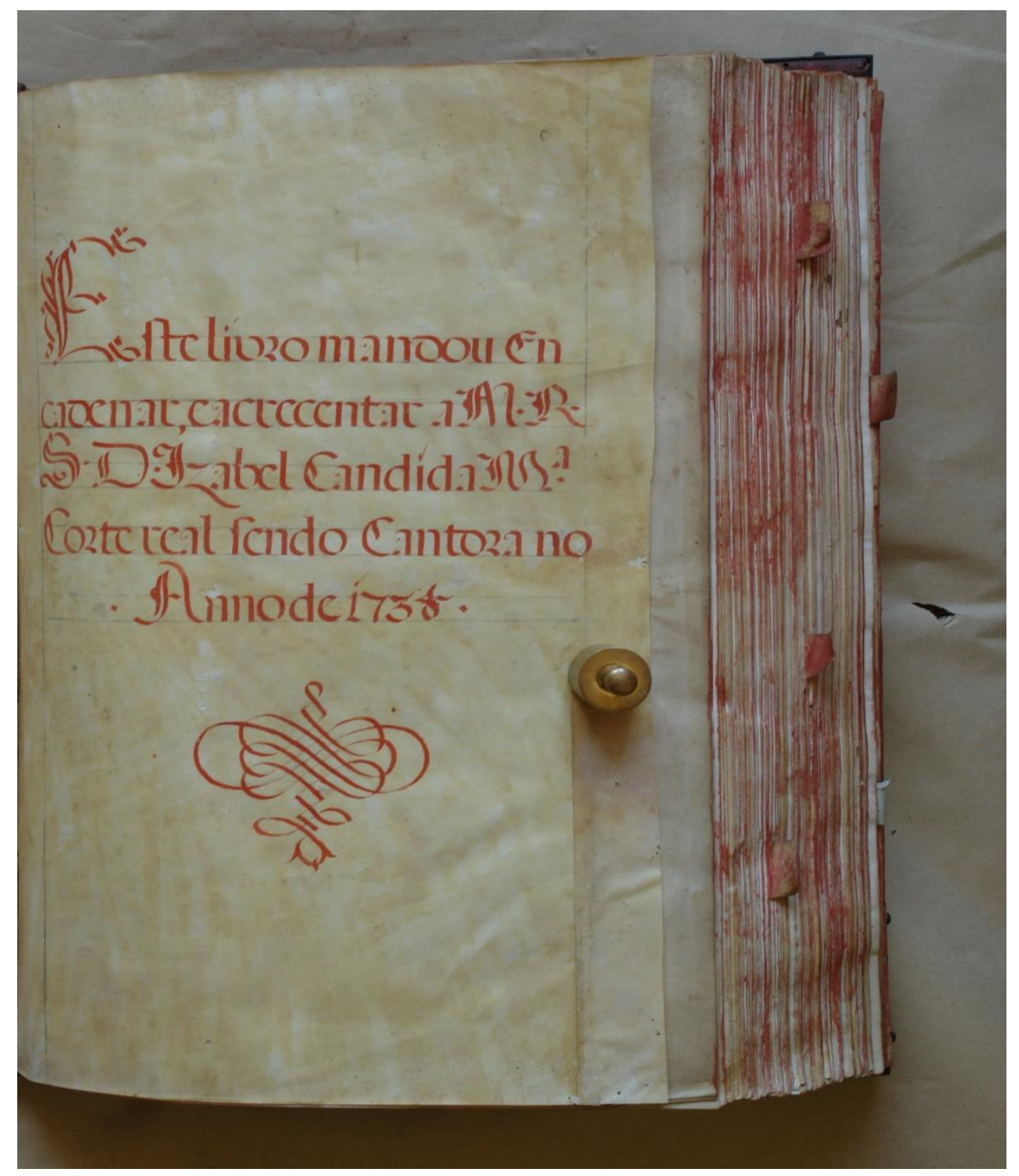

Figura 1. P-EVad 32: folha de guarda - inscrição inicial

Enegrecido pelo uso, inclui alguns acrescentos e trechos musicais colados posteriormente, bem como diversas anotações posteriores de vária ordem, quer litúrgicas, interpretativas ou teórico-musicais. Um dado que importa sublinhar desde já assenta no facto de existirem várias secções melódicas apagadas através de raspagem, cuja intenção foi muito provavelmente, lançamos aqui essa hipótese, a simplificação dos cânticos de acordo com os ditames tridentinos (v. fig. 2). ${ }^{22}$

${ }^{22}$ Cf. nota 16. 


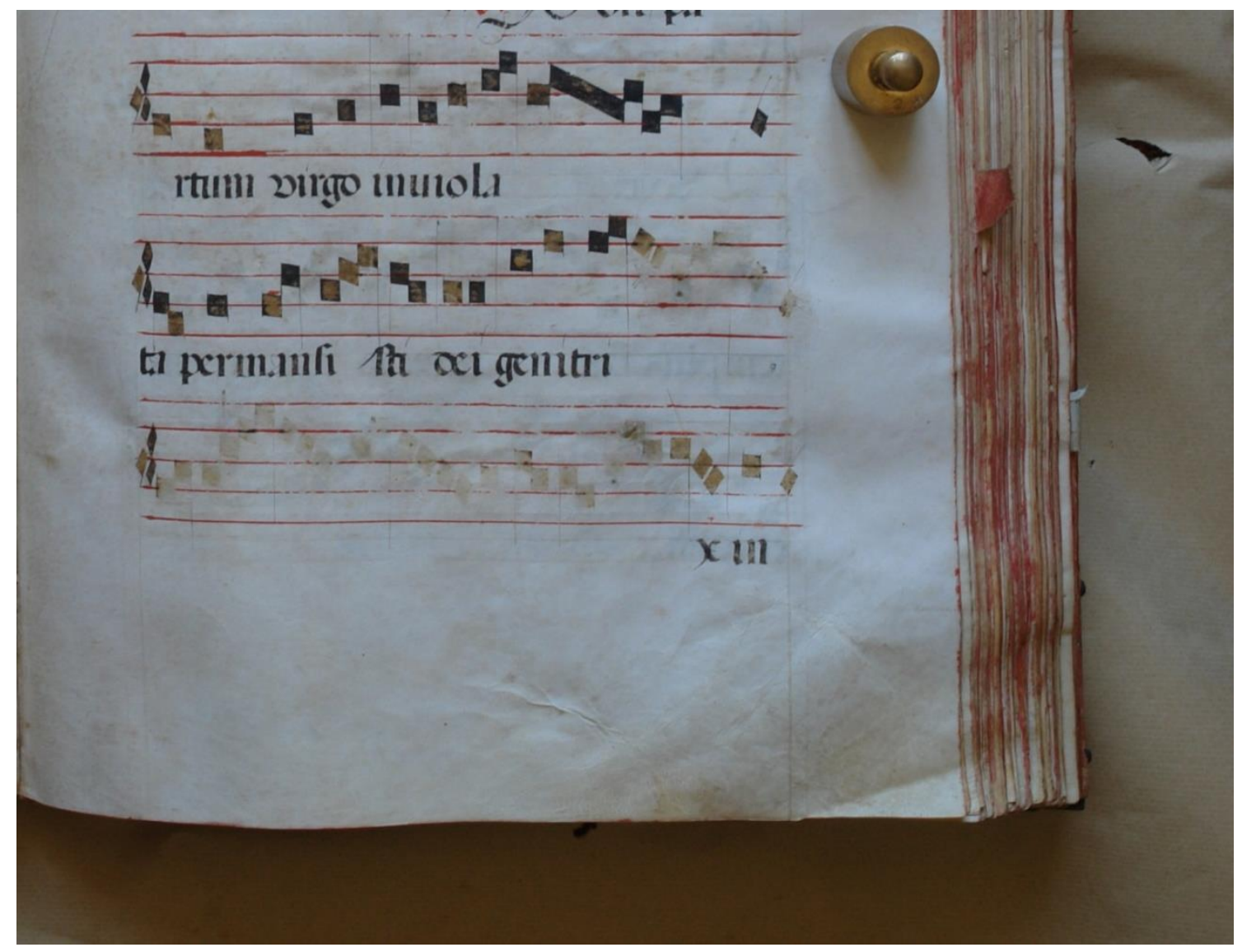

Figura 2. P-Evad 32, f.101: margem inferior - trecho melódico apagado

Importa destacar também, o facto de incluir uma composição atribuível a Mateus d’Aranda, dispersa em vários fólios por questões de reencadernação. Trata-se do trecho inicial do motete Et incarnatus est, cujo Tiple e o Tenor se encontram no verso do fólio CLXVII (167) da numeração original romana (v. fig. 3). 


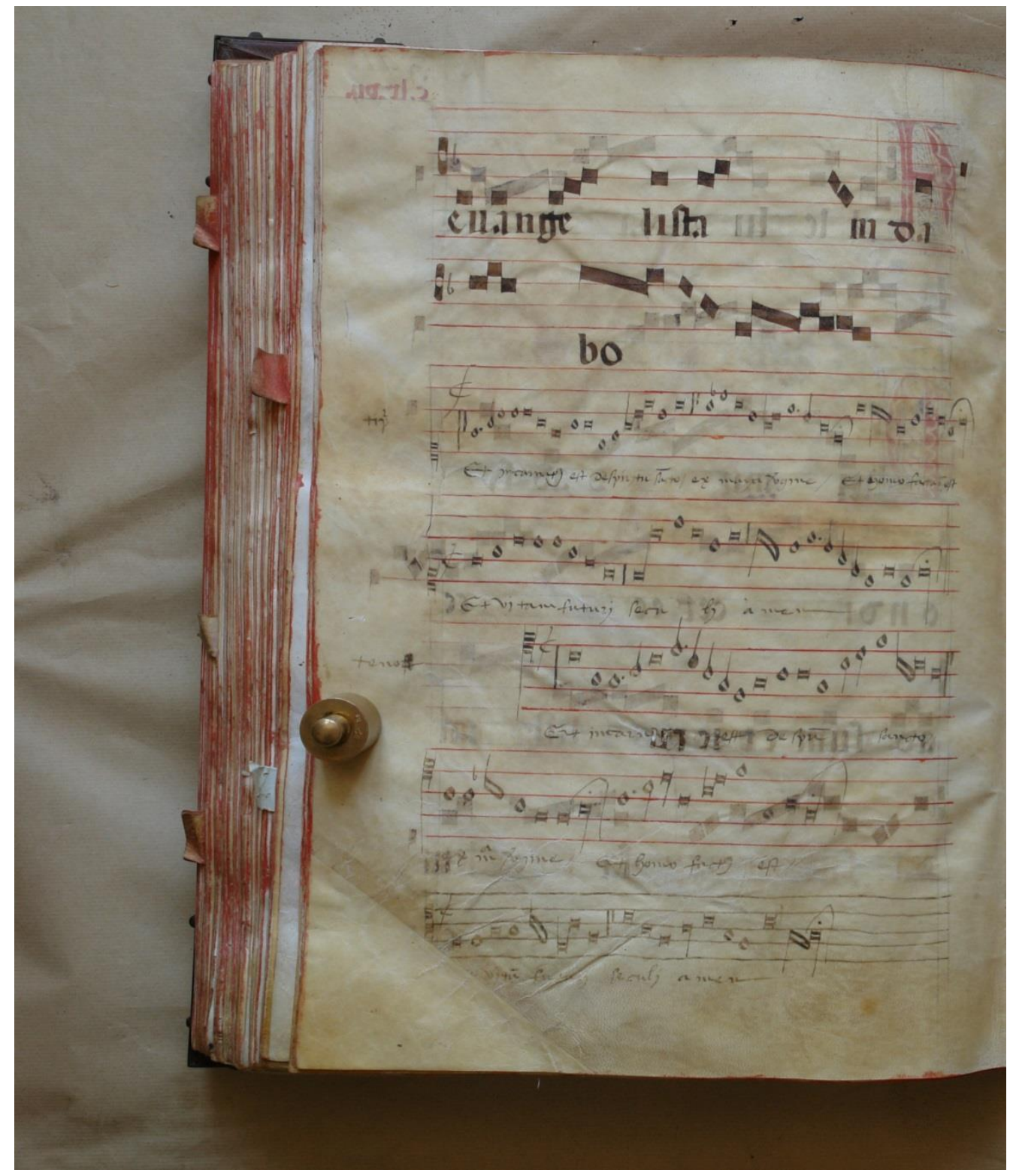

Figura 3. P-Evad 32, f. CLXVIIv: acrescento polifónico - trecho inicial do motete Et incarnatus est atribuído a Mateus d'Aranda (Tiple e Tenor)

O fólio seguinte CLXVIII (168) encontra-se inserido no final da encadernação e inclui, na sua face recto, as vozes de Altus e Bassus da mesma composição polifónica (v. fig. 4). 


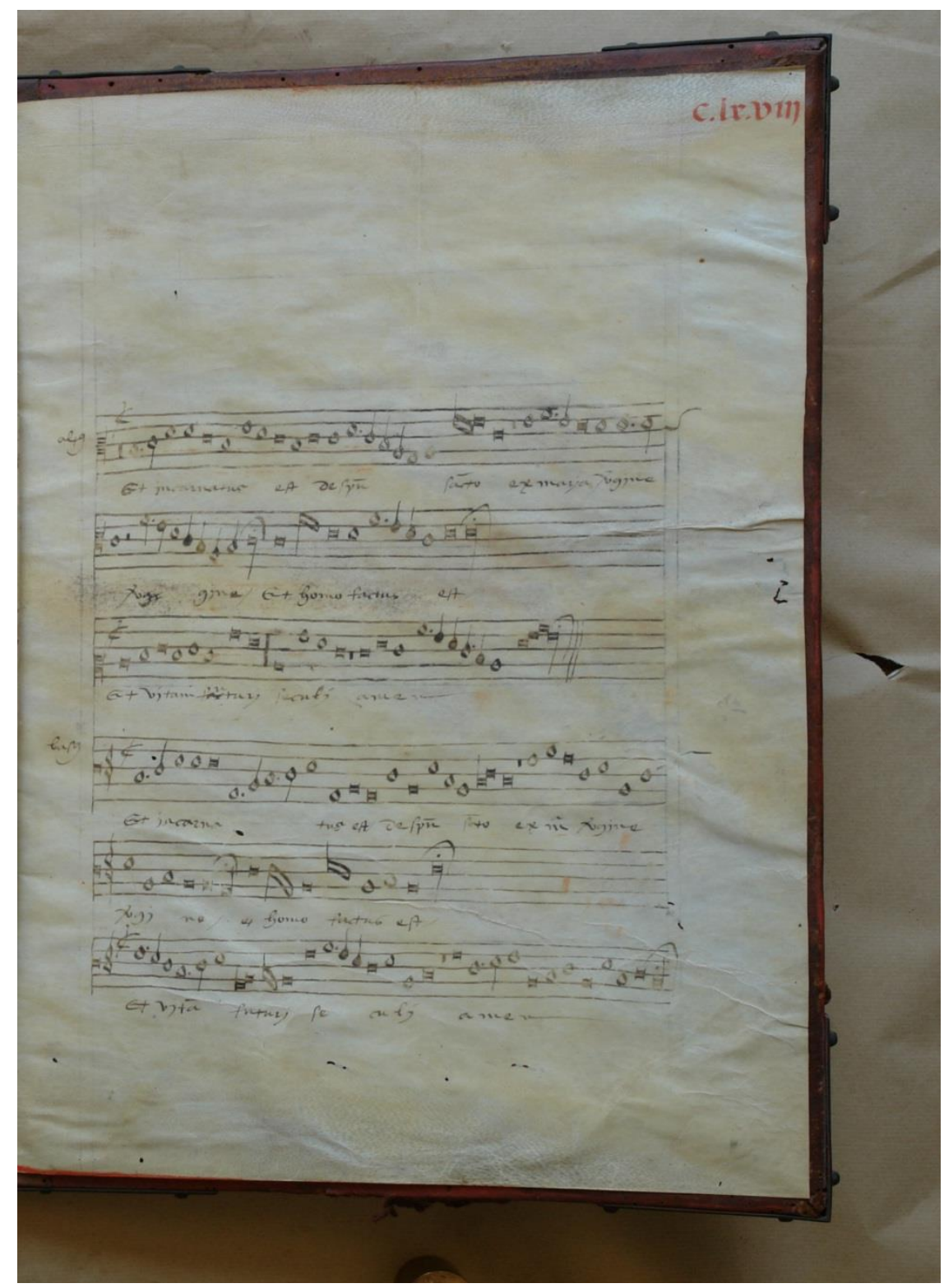

Figura 4. P-Evad 32, f. CLXVIIIr: acrescento polifónico - trecho inicial do motete Et incarnatus est atribuído a Mateus d’Aranda (Altus e Bassus)

$\mathrm{Na}$ sua face verso deparamo-nos com outro trecho polifónico, desta vez constituído pelas respostas a 4 vozes à introdução do Prefácio, nomeadamente os, Tiple, Altus, Tenor e Bassus. A leitura é difícil, pois a cópia encontra-se bastante deteriorada. Pela análise caligráfica, sabemos que o copista destas respostas foi o mesmo que copiou o motete de Mateus d'Aranda (v. fig. 5). 


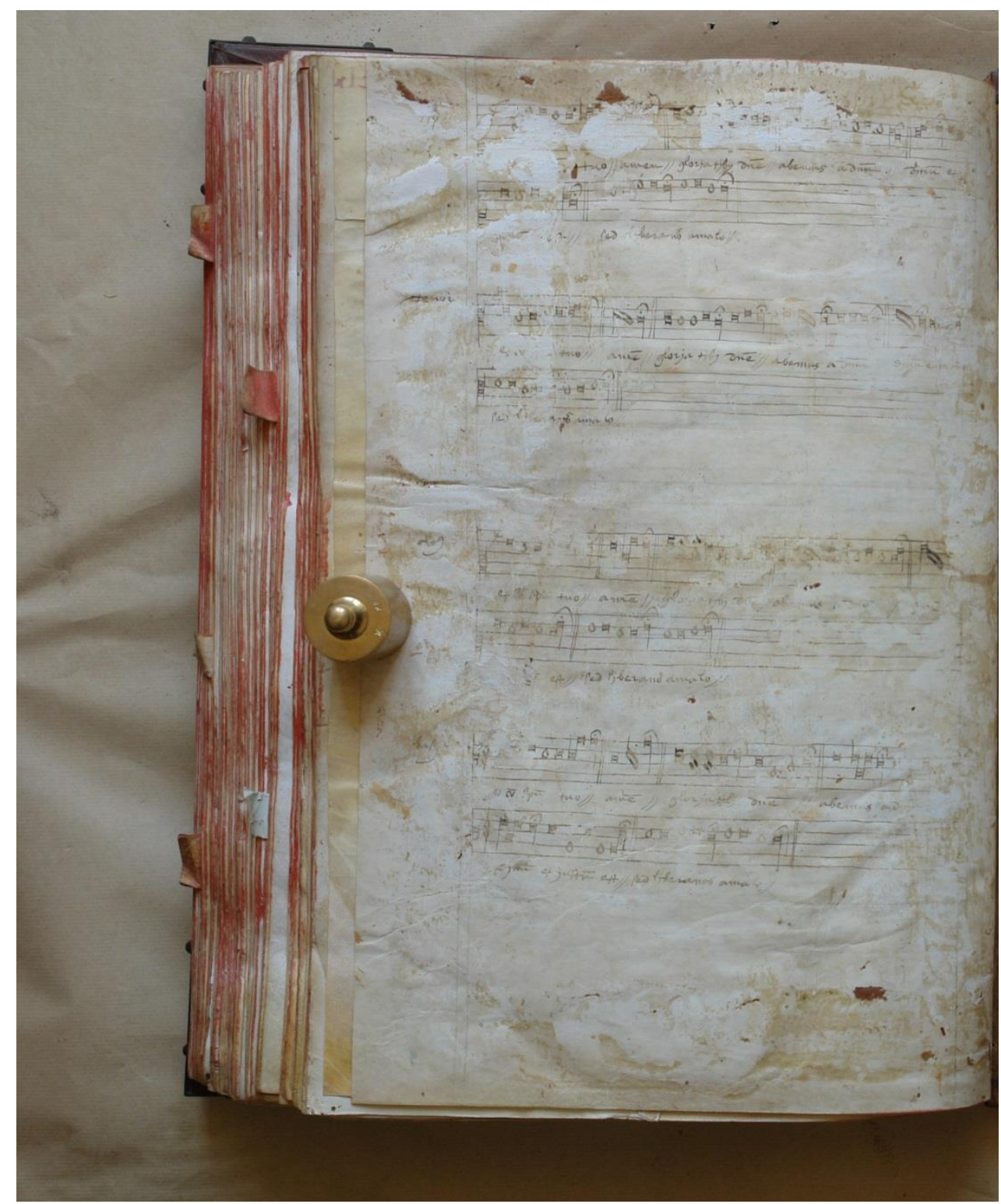

Figura 5. P-EVad 32, f. CLXVIIIv: acrescento polifónico - Introdução ao Prefácio (Tiple, Altus, Tenor e Bassus)

Embora praticamente constituído por monodia, para além destes breves acrescentos polifónicos, o códice inclui algumas instruções de execução musical, essencialmente na sua parte final, que nos levam ao encontro da tese que atrás expusemos. Assim, no fólio 353 e seguintes, existem uma série de referências de execução, atestando a alternância prelúdio/coro, que nos provam que, a preceder as diversas secções do Sanctus, eram tocados prelúdios, muito provavelmente para órgão, dada a natureza de cariz harmónico desta forma musical (v. fig. 6). 


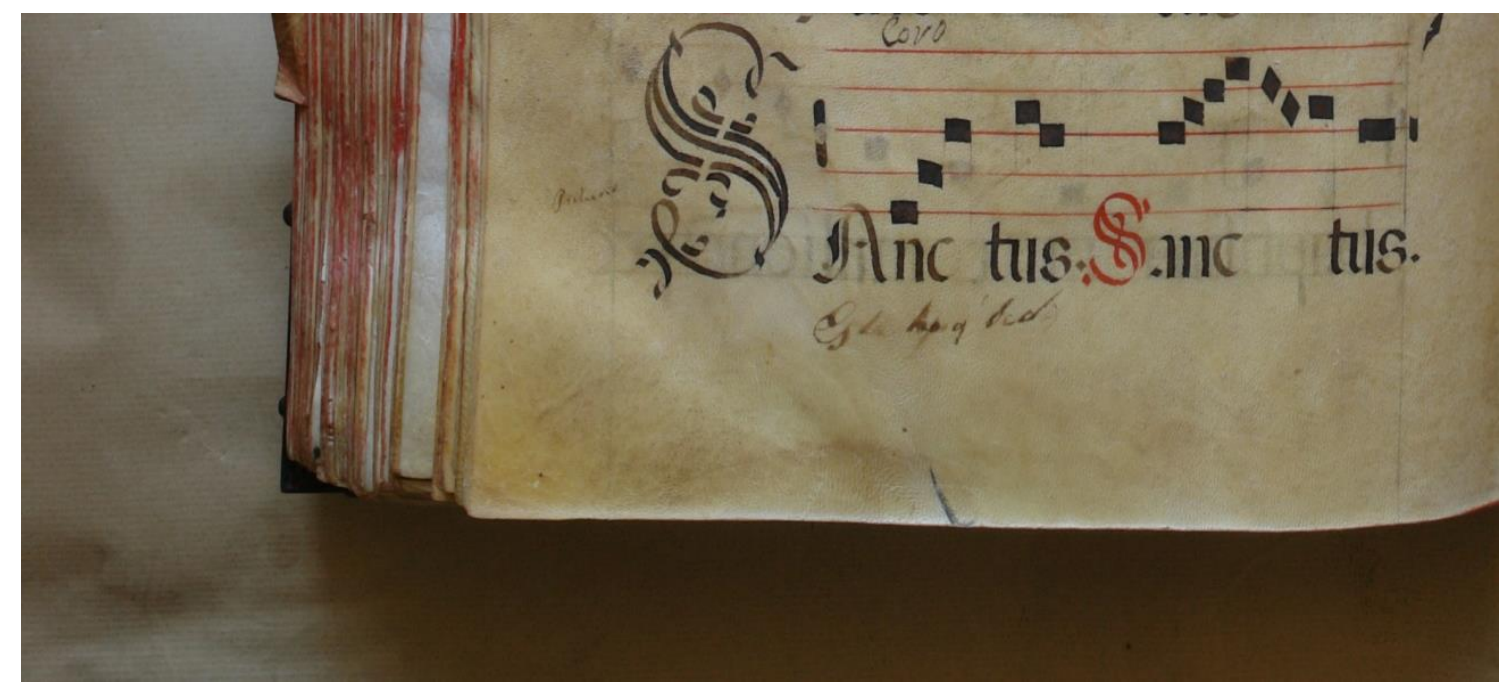

Figura 6. P-EVad 32, f. 353: margem inferior - anotação indicando «Prelúdio» pressupõe execução organística

Deduzindo, a estrutura formal do discurso musical seria então: Prelúdio de órgão; Coro - 1 Sanctus, Sanctus, Sanctus e 2 - Domine Deus Sabaoth; Prelúdio de órgão; 3 - Pleni sunt caeli et terrae gloria tua, hosanna in exclesis (v. fig. 7).

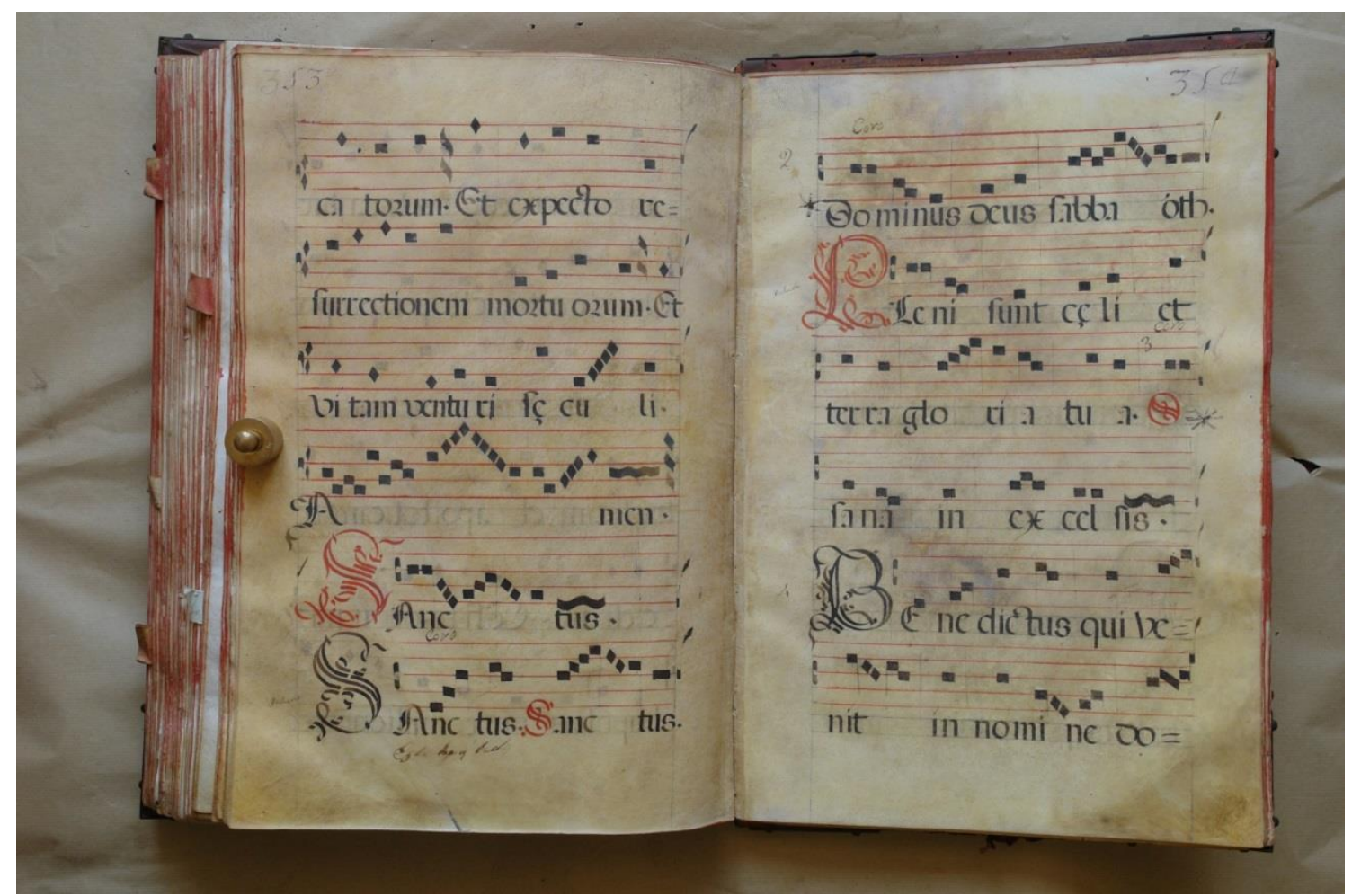

Figura 7. P-EVad 32, ff. 353-4: anotações sobre a estrutura formal da execução musical 
Por outro lado, encontramos uma anotação na margem esquerda do fólio 328 que explicita objectivamente prática instrumental. Refere ela o seguinte: «fica o órgão em de la sol re» (v. fig. 8).

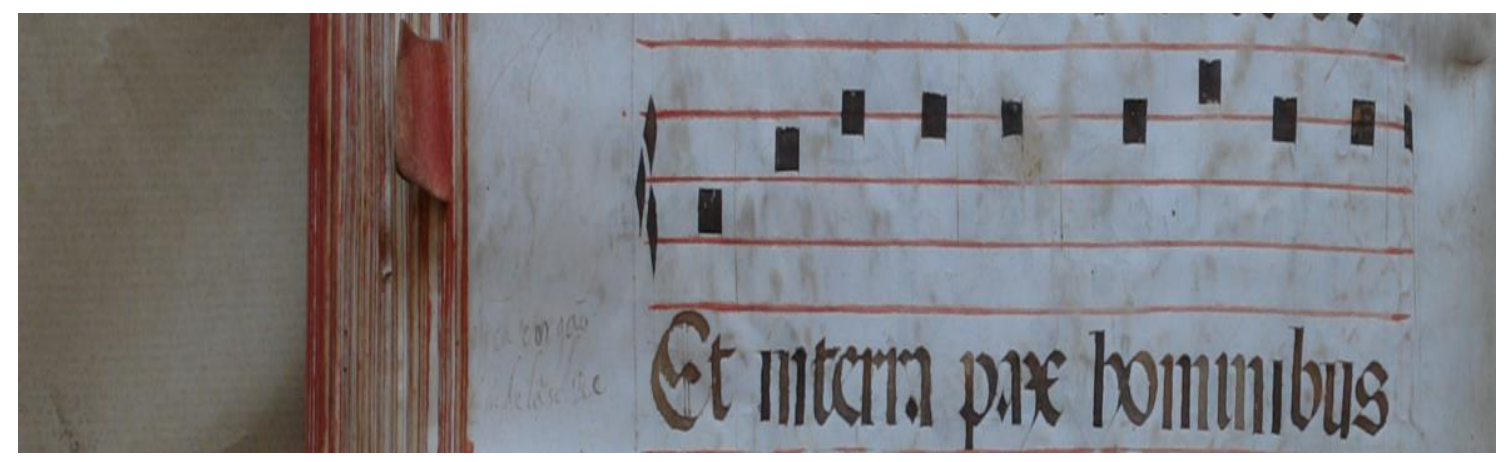

Figura 8. P-EVad 32, f. 328 (excerto) - anotação salientando: «fica o órgão em de la sol re»

Várias são as conclusões que daqui podemos extrair. Em primeiro lugar a referência ao órgão. A este propósito convém lembrar que, durante o século XVI e grande parte do XVII, sobretudo em culturas limítrofes como a portuguesa, nas fontes documentais que dispomos os instrumentos quase nunca vêm especificados. Quer isto dizer que, para além do órgão cuja existência física no espaço do templo atesta o seu decorrente uso litúrgico, há toda uma plêiade de instrumentos de corda e sopro que seriam também tocados, como consta nos dotes das monjas de Cástris ${ }^{23}$. Eram portanto de certeza tocados, embora não saibamos o seu enquadramento em matéria de execução no âmbito das festividades litúrgicas. Voltando à anotação do fólio 328 , ela explicita 0 hexacorde de la sol re, facto que pressupõe a fixação do discurso musical a partir daí em determinado hexacorde, neste caso o durum. Trata-se de uma ajuda de entoação para coro, que seguirá cantando o Gloria (v. fig. 8, p. 13). Ora, este dado vai ao encontro do que atrás referimos, isto é, o papel do órgão não se cinge aqui apenas à execução de peças instrumentais como são os versos, hinos ou tentos, mas sim tem um papel de direcção e suporte à execução coral, dando a ouvir os tons em questão ou os hexacordes nos quais irão ser cantados esses tons, como aqui é o caso. Mau grado termos apenas uma anotação deste tipo em todo o manuscrito 32, o que poderia surgir como uma excepção, o facto é que não se trata de uma excepção, mas sim de uma regra. É lícito admitirmos que, ao longo de todas as rubricas que o manuscrito inclui, o órgão pudesse

\footnotetext{
${ }^{23}$ CONDE, Antónia Fialho, O mosteiro de S. Bento de Cástris e a Congregação Autónoma de Alcobaça
} (1567-1776), Universidade de Évora, Tese de Doutoramento em História Moderna, Julho de 2005. 
ser utilizado, ora tocando versos ou outras formas, ora ajudando o coro a entoar. Há também aqui uma questão que se prende com a datação das várias anotações que foram sendo acrescentadas ao manuscrito, cujo âmbito cronológico certamente abrange quase dois séculos, se tivermos em conta que as cópias mais antigas datam do século XVI e à encadernação se associa a data de 1738. Portanto, o códice foi sendo sempre utilizado para execução musical ao longo dos tempos e muitas das anotações posteriormente acrescentadas revelam a sua adaptação a novos critérios estilísticos, um dos quais é a presença cada vez mais acentuada dos instrumentos musicais na liturgia, à medida que o tempo passa.

Concluímos, sublinhando que o Manuscrito Musical 32 do Arquivo Distrital de Évora (P-EVad 32) constitui uma fonte de dados sobre a música no espaço cisterciense de S. Bento de Cástris, durante praticamente trezentos anos da sua história. O aflorar da questão instrumental, como ficou exposto, constitui apenas uma das muitas vertentes através das quais podemos fazer a abordagem musicológica deste códice. Não sendo todavia central em termos científicos, fica contudo aqui a problematização de alguns aspectos que, sem dúvida, nos remetem para a prática instrumental. Importará de futuro fazer o estudo sistemático do enquadramento vocal litúrgico do Manuscrito 32, muito em concreto sobre as modificações de que foi sendo alvo em função das directivas tridentinas. Para já inaugurámos aqui este breve filão temático da execução instrumental, na esperança que futuras gerações de musicólogos possam vir a enriquecer o nosso conhecimento musical de tão rico património histórico. 
